\title{
Colour preferences and personality traits
}

\author{
Reidulf G. Watten ${ }^{1}$, Knut Inge Fostervold ${ }^{2}$
}

1) Department of Psychology, Inland Norway University of Applied Sciences, Norway

Email: reidulf.g.watten@inn.no

2) Department of Psychology, University of Oslo, Norway

Email: k.i.fostervold@psykologi.uio.no

Correspondence to: reidulf.g.watten@inn.no

Declaration of Interest:

None 


\begin{abstract}
Colours are important features in human and natural environments and are related to several psychological functions. However, a possible relation between colour preferences and personality traits is scarcely investigated. The aim of the present study was to find out whether differences in preferences for colours also reflected differences in Big Five personality traits. The sample consisted of 206 individuals voluntarily recruited from a student sample. The participants chose one of six primary colours (blue, green, red, yellow, black, white) from the Natural Colour System (NCS) as their favorite colour. Personality traits were measured with the Big Five Inventory-44 (BFI-44. Blue and yellow was the most and least preferred chromatic colour, respectively. There were no gender differences in preferences for the chromatic colours, but more women preferred white and men preferred black. Compared to the rest of the sample, the blue group had higher scores on agreeableness and extraversion, and the red group had lower scores on agreeableness. Pairwise comparisons showed that the blue group had higher scores on agreeableness and extraversion than the red group, and higher scores on agreeableness compared to the green group. There were no significant personality differences for the other chromatic and achromatic colour groups.
\end{abstract} Key words: colours, preferences, personality traits, agreeableness, extraversion 


\section{Introduction}

Colours are important characteristics of our natural and human made environments. Colours are related to several psychological functions and have been subject to scientific research for more than 100 years [1]. For instance, Jastrow [2] conducted a comprehensive population study on colour preferences where the participants were recruited from visitors to the World's Columbian Exposition held in Chicago in $1893(\mathrm{~N}=4556)$. He found that blue was the most preferred colour, indeed, a number of studies have since confirmed Jastrow's results [3-7]. However, the factors behind explaining the colour preferences have been a matter of considerable dispute.

Due to the trichromatic nature of the sensory visual system it is not surprising that a universal theory of colour preferences has been posited [8]. One version is The Ecological Valence Theory (EVT) suggesting that colour preferences have an adaptational purpose since colours are conveying visual information which is fundamentally important for survival, wellbeing and safety [3]. Therefore, colour preferences could be based on basic functions of the visual system. However, universal colour preferences seem not to be the case. Investigating colour preferences in British adults and Himba adults from rural areas in Namibia Taylor, et al. [9] found marked differences between the two groups. Contrary to the British, the Himba participants had low preference for bluish "universal" colours, but higher preference for red, orange, and yellow. These findings strongly suggest that colour preferences are not universal resulting from "hardwired" neurobiology. Rather, they reflect a dynamic process influenced by several factors. For example, seasonal variations in our surroundings (winter, spring, summer, autumn) can affect colour perception. There is a shift towards shorter wavelengths in the summer compared to winter, probably a long-term habituation to cone inputs due to the amount of reflected greenish light in the spring-summer [10]. Latitude also seems to play a role. Individuals born above the Arctic Circle seem to find it difficult to discriminate yellow- 
greenish hues, compared with shorter wavelengths such as purple-indigo, hues which are more prominent during the winter season [11]. Gender differences have been reported, women seem to prefer warmer colours, shades of blue preferred by men $[5,8]$, Indeed, historically men were hunters and women predominantly gatherers, and colours could signal different information of survival value in the domains of living for women (reddish colours signal ripe fruit, green freshness of vegetables) and men (blue signals clear water, sky)[1215]. Cultural differences are also described, individuals of Japanese origin seem to dislike red, in contrast to Americans who like red very much. On the other hand, Japanese prefer white, which could be as the colour white has a symbolic meaning of cleanness in Japan [16]. Sorokowski, Sorokowska and Witzel [14] reported gender and culture differences between a Polish and Papua-Indonesian sample. The Polish participants preferred purpure-blue, whereas Papua sample preferred yellow and red. Thus, it seems that geographic and sociocultural factors and cultural learning are important in colour preferences.

Colours are also associated with emotions and this issue has been described in several studies from various research traditions. For instance, targets presented in red hue seem to be associated with dominance and braveness, and in an evolutionary perspective red could, therefore, be seen as a signal of competitiveness and social dominance possibly linked to underlying testosterone levels [17]. Marketing research has shown blue is associated with trust more than red [18], whereas red is associated with dominance [19]. Red is also associated with erotic feelings. Experiments have shown that red lead men to see women as more attractive and sexually desirable [20], but also leading women to see men as more attractive. However, this female effect was linked to social status perception [21]. Furthermore, exposition to red could have basic physiological arousal and motivational effects, it seems to enhance motor velocity and force [22]. 
Despite the research on colours and emotions, very few studies have attended to the direct relationship between personality and colour preferences in recent years. However, a previous review published in 1963 (contemporary research at the time), showed no support for an association between colours and personality factors such as impulsivity, suggestibility and emotionality, but reduced use of colors among depressed individuals [23]. The paucity of studies on colours and personality is somewhat surprising since emotions are a fundamental part of the dispositional domain of personality[24,25]. Emotions are not only transitory states, but also emotional traits, patterns of emotional experiences and consistent reactions that are stable across a variety of situations and typical for individuals [26]. For instance, negative emotions are typically related to Neuroticism and positive emotions to Extraversion [27,28]. This integration of emotions in the personality structure raises a methodological issue: Studies reporting associations between emotions and colour preferences could be reporting emotional traits in the personality. It is therefore pertinent to examine the relationship between colour preferences and personality traits.

Previous studies on emotions evoked by colours are from a personality point of view quite interesting $[1,29]$. For instance, Wu and Lin [30] showed how single colours could evoke personality associations as indicated by brief Big Five trait markers [31]. One of the findings were that increased chroma in the blue-greenish area evoked a more agreeable impression, whereas colours in the yellow showed the opposite effect. Although interesting from a colour science perspective, a more robust methodological approach would be to conduct an assessment of individuals' colour preferences linked to personality traits in the same individual. As far as we know, only the study of Fetterman, et al. [32] has applied this methodological approach. The authors investigated the relationship between one colour - red and interpersonal hostility measured by the warmth-coldness scale of the Revised Interpersonal Adjective Scale (IAS-R) based on the circumplex personality model of 
personality [33]. They found that preference for red was associated with higher scores in hostility. Although Wiggins' circumplex model of personality is well recognized, shortcomings with respect to relations between emotions have been discussed for some time [34,35]. Therefore, assessments based on the Big Five theory are both more appropriate with respect to trait profiles, and more widely used. Moreover, the relationship between preferences for basic colours such as black, white, blue, red, green, and yellow and personality traits assessed with Big Five instruments has not been described so far.

The aim of the current study was to find out if differences in colour preferences also reflect differences in personality traits. For example, are there differences in personality traits between those who prefer blue vs. those who prefer red? We used a Big Five personality test (BFI-44) to assess the trait profile of participants preferring one of the six primary colours of the Natural Colour System (NCS: white, black, yellow, red, blue, green).

\section{Materials and Methods}

\subsection{Participants}

The participants were recruited in an opportunity sampling of students taking part in lectures in psychology at INN university, Norway. The total sample consisted of 206 individuals $(\mathrm{n}$ women $=145, \mathrm{n}$ men $=61)$ with a mean age of 23.2 years $(\mathrm{SD}=4.82)$.

\subsection{Assessment of basic colours}

We used the Natural Colour System [36] to register primary colours. That system is widely used both among various professions and researchers [37-39]. In the current project we used only the basic colours of which there are six: the two achromatic colours black and white, and four chromatic colours: yellow, red, blue, and green (see fig. 1). The participants were selected into six groups according to their preferred colours: white $(1=$ yes, $2=$ no), black $(1$ 
= yes, $2=$ no $)$, yellow $(1=$ yes, $2=$ no $)$, red $(1=$ yes, $2=$ no $)$, green $(1=$ yes, $2=$ no $)$, and blue ( $1=$ yes, $2=$ no). The participants had to choose one of those colours as their favorite colour. This meant that each colour group, for instance red, was compared to the rest of the sample who did not choose red. In addition, pairwise comparisons between the colour groups were examined (blue vs. red, blue vs. green etc.)

Insert fig. 1 about here

\subsection{Personality traits}

Personality traits were measured with the Norwegian version of the Big Five Inventory-44 (BFI-44) [40]. The BFI-44 consists of 44 items assessing five dimensions: extraversion (E), agreeableness (A), conscientiousness (C), emotional stability (ES; neuroticism reversed), and openness to experience (O). Example of two items from the scales: E - "Is talkative", "Generates a lot of enthusiasm "; A - "Is helpful and unselfish with others", "Has a forgiving nature"; C - "Does a thorough job", "Is a reliable worker"; ES - "Is relaxed, handles stress well", "Remains calm in tense situations"; $\mathrm{O}$ - "Is original, comes up with new ideas", "Has an active imagination". The answers were registered on a 7-steps Likert scale where 1 = disagree strongly $7=$ agree strongly. The BFI shows acceptable internal consistency (Cronbach's alpha coefficients between .75- .90 and test-retest reliability between $.80-.90)$. Reliability estimates for the Norwegian version are comparable to international studies [40]. The alpha coefficients $(\alpha)$ of the present sample were the following: extraversion .88; agreeableness .70; conscientiousness .82; emotional stability, .73; and openness to experience .81 . 


\subsection{Procedure.}

The colours and the personality test were printed out on a standard white 80 gram A4 paper and filled out collectively in an auditorium, i.e. a paper-and-pencil procedure. Filling out the questionnaires took about 5-7 minutes. The ambient light was measured on 14 different places in the auditorium where the students were sitting using a Hagner Photometer Screen Master (B. Hagner AB, Solna, Sweden). The mean value of reflected light from the 14 places was $103.3 \mathrm{~cd} / \mathrm{m}^{2}(\mathrm{SD}=10.3$, range $82.3-117.5)$. Spectrometric measurements of the NCS colours were carried out using the NCS spectrometer Model RM 2000 (NCS Testing Technology Co., Ltd., Beijing, China). The measurements were conducted directly on the printed colours of the paper and yielded the following results: yellow - S0540-G90Y; red S1070-Y90R; green - S2050-B90G, and blue - S1560-R90B; and. The graphical quality of the colours was slightly reduced in the copying process, but the hues of the achromatic and chromatic colours were not changed.

\subsection{Statistical analyses}

In addition to descriptive statistics and Pearson Chi-squares for testing gender differences in colour preferences, we also conducted multivariate analyses of variance (MANOVA) using the personality traits as dependent variables and the NCS groups or pairs of colours as independent variables (Red $1=$ yes, $2=$ No). Example of pairwise comparison: blue-red pair: blue $=1$, red $=2$. If there were gender differences among the NCS groups in colour preferences gender was used as a covariate in the analyses to control for that effect. The analyses were carried out with the Statistical Package for the Social Sciences (SPSS) version 26.

\subsection{Ethics}


The study was conducted in agreement with the ethical principles of the Helsinki declaration [41]. Participation was voluntary and the participants made a written consent prior to taking part in the experiment. The participants were also informed that they could withdraw from the study at any time and without justification. The questionnaires were completed anonymously in a collective teaching situation. After collection, each questionnaire was given a serial number (from 1 to 206) so respondents could not be identified.

\section{Results}

Table 1 shows the rank order of frequency of preferences of the primary colours. Blue was the best liked colour, $42.2 \%$ preferred blue, white was least preferred, only $7.8 \%$ of the total sample had white as a favourite, whereas yellow was the least liked among the four chromatic colours $(11.2 \%)$ 
Table 1. Rank order of frequency for preferences of NCS primary colours in the total sample.

n $\%$

$\begin{array}{lcc}\text { 1. Blue } & 87 & 42.2 \\ \text { 2. Green } & 35 & 17.0 \\ \text { 3. Red } & 28 & 13.6 \\ \text { 4. Yellow } & 23 & 11.2 \\ \text { 5. Black } & 17 & 8.3 \\ \text { 6. White } & 16 & 7.8\end{array}$

Total n $\quad 206 \quad 100$

Table 2 shows the gender distribution of colour preferences. We found significant gender differences for the achromatic colours black and white. The vast majority of those who chose white as their favourite colour were women: 15 out of totally 16 participants, $\chi 2(1)=4.54, p$ $=.033$, Cramer's $\mathrm{V}=.148$. In contrast, men preferred black, $\chi 2(1)=4.84, p=.028$, Cramer's $\mathrm{V}=.153$. There were no significant gender differences for the four chromatic colours, but there were interesting differences in ranking of the chromatic colours: 1. blue, 2. green, 3. red 
and 4. yellow were the female ranking. The male rank order was 1. blue, 2. green, 3. black, 4 . red and 5. yellow.

Table 2. Gender differences in rank order and preferences for NCS primary colours. Pearson Chi-square tests.

Women Men

$\begin{array}{llllll}\text { Rank } & \mathrm{n} & \text { \% gender } & \mathrm{n} & \% \text { gender } & \mathrm{n} \text { total }\end{array}$

\begin{tabular}{|c|c|c|c|c|c|c|c|}
\hline 1. Blue & 58 & 40.0 & 1. & 29 & 47.5 & 87 & .199 \\
\hline 2. Green & 24 & 16.6 & 2. & 11 & 18.0 & 35 & .471 \\
\hline 3. Red & 22 & 15.2 & 4. & 6 & 9,8 & 28 & .215 \\
\hline 4. Yellow & 18 & 12.4 & 5. & 5 & 8.2 & 23 & .268 \\
\hline 5. White & 15 & 10.3 & 6. & 1 & 1.6 & 16 & .024 \\
\hline 6. Black & 8 & 5.5 & 3. & 9 & 14.8 & 17 & .031 \\
\hline
\end{tabular}


Table 3 shows the MANOVA results for the chromatic colours compared to the rest of the sample. We found significant differences in personality traits for three colours: black, red, and blue. The black group had higher scores in openness $(F(1,201)=5.50, p=.020)$. However, when we controlled for gender (more men than women preferred black), the differences were no longer significant $(F(1,200)=3.21, p=.075)$. The red group had significantly lower scores in agreeableness compared to those who did report red as their favourite colour $(F$ $(1,201)=7.01, p=.009$, Observed Power $=.750$. There was a significant gender difference in agreeableness $(F(1,201)=5.79, p=.017)$, women had higher scores than men, but when we controlled for gender, the red group still had significantly lower agreeableness scores $(F$ $(1,201)=8.30, p=.004$, Observed Power $=.818)$. On the contrary, the blue group had significantly higher scores on agreeableness when controlled for gender $(F(1,200)=8.07, p=$ .005 , Observed Power $=.807$. The blue group was also more extraverted $(F(1,200)=6.38, p$ $=.012$, Observed Power $=.710$. There were no significant personality differences for the white, yellow, and green groups. 
Table 3. Preferences for NCS primary colours and personality traits. Preferred colour group (Yes) compared to the rest of the sample not preferring that colour (No). Multivariate analysis of variance controlled for gender (MANCOVA)

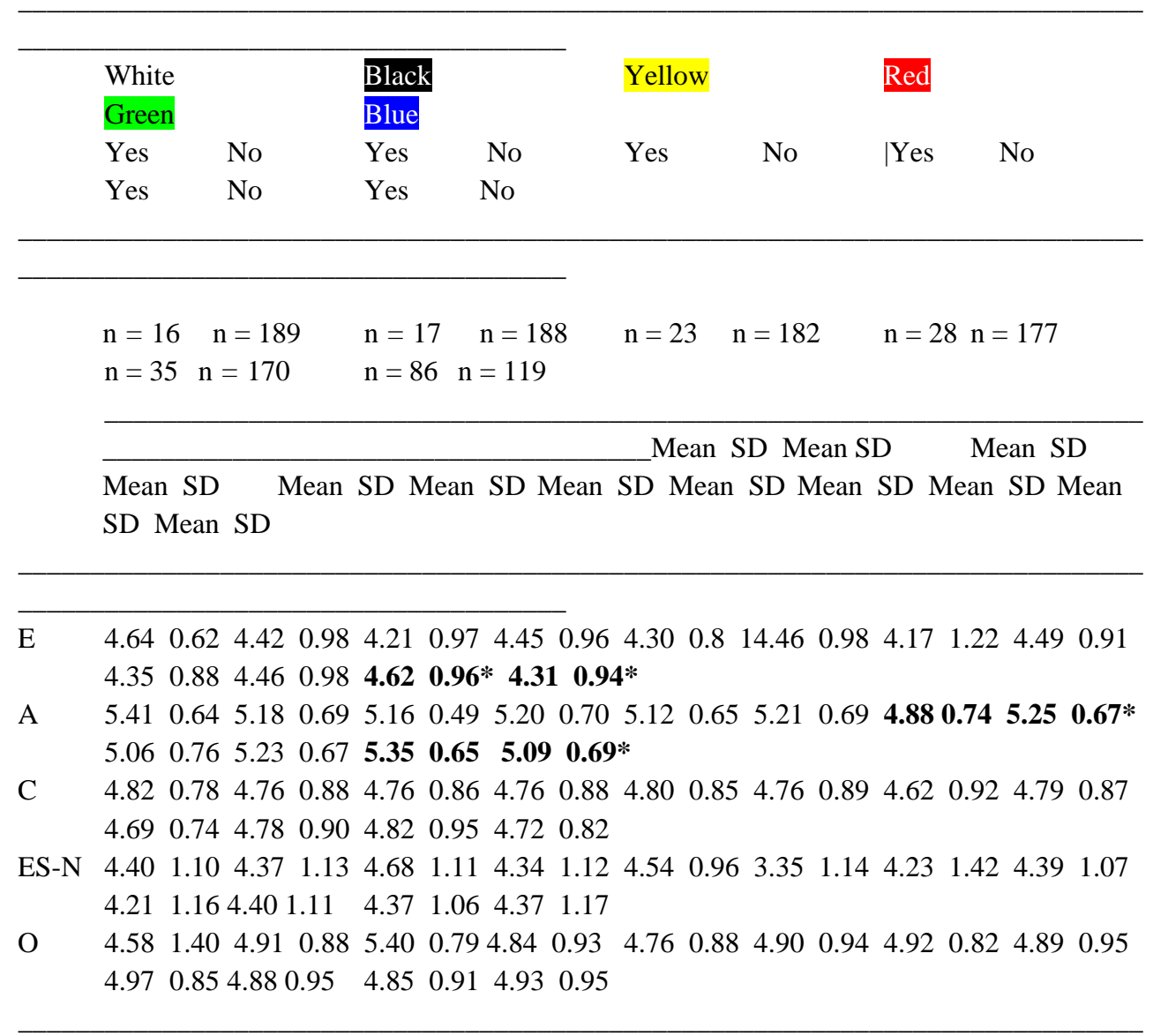

Note $: \mathrm{E}=$ extraversion; $\mathrm{A}=$ agreeableness; $\mathrm{C}=$ conscientiousness; $\mathrm{ES}-\mathrm{N}=$ emotional stabilityneuroticism; $\mathrm{O}=$ openness to experience. Significant differences are marked in boldface and italics; $*=p<.05$.

Table 4 and shows the results for paired comparison between the chromatic pairs blue-red, blue-green and the blue-yellow group. Compared to red, the blue group had significantly higher scores on extraversion $(F(1,111)=4.36, p=.039$, Observed Power $=.544)$, and agreeableness $(F(1,111)=10.01, p=.002$, Observed Power $=.880)$. The blue group also had higher scores than the green group on agreeableness $(\mathrm{F}(1,117)=4.32, p=.040$, Observed Power $=.541)$. There were no significant differences for the blue-yellow pair. 
Table 4. Personality traits and colour preferences. Pairwise comparisons of NCS primary chromatic colours: blue-red, blue-green, blue-yellow. Multivariate analyses of variance (MANOVA).

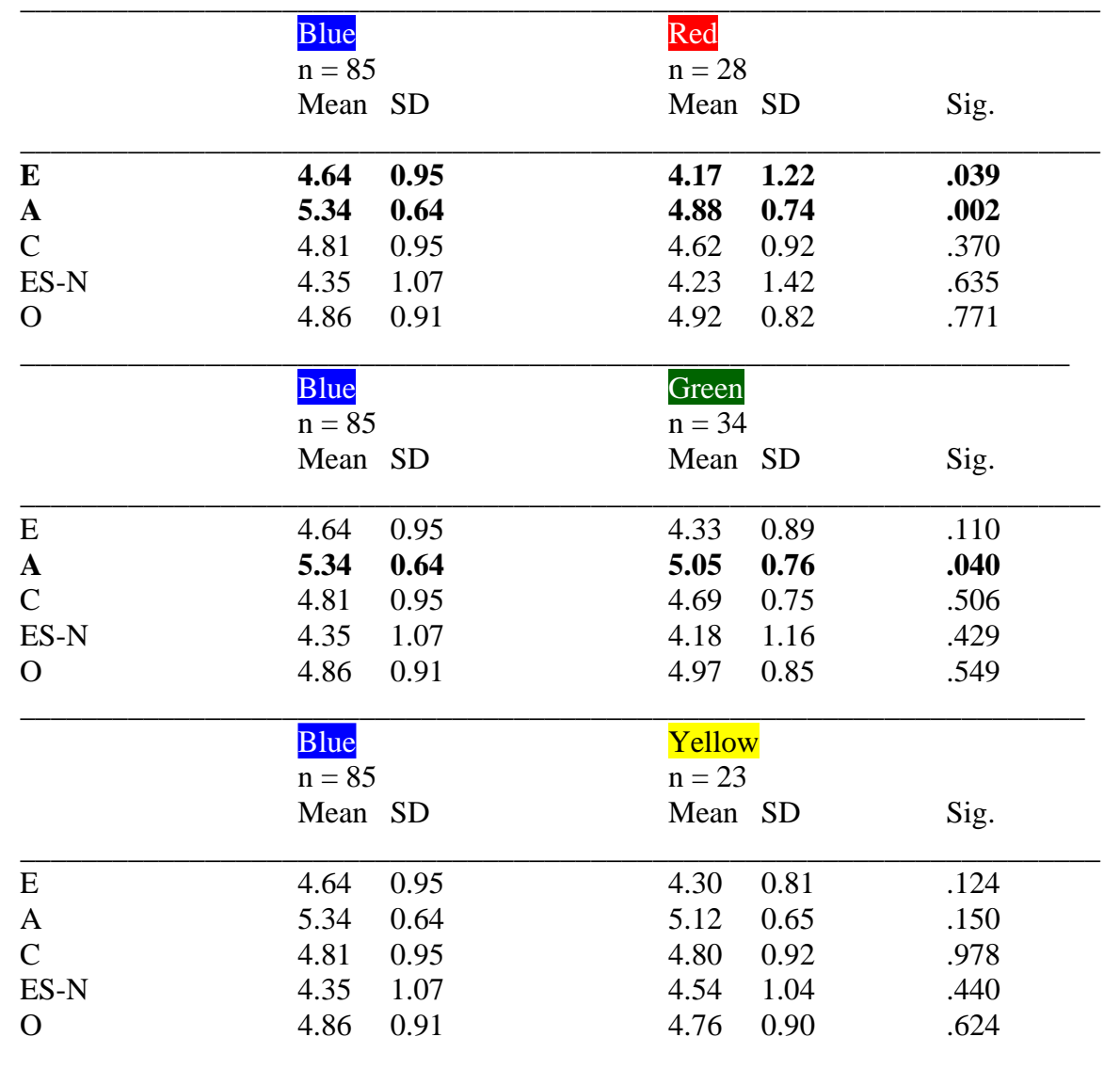

Note: $\mathrm{E}=$ extraversion; $\mathrm{A}=$ agreeableness $\mathrm{C}$ = conscientiousness; $\mathrm{ES}=$ emotional stabilityneuroticism; $\mathrm{O}=$ openness to experience. Significant differences are marked in boldface.

Table 5 depicts the results for the pairwise comparison between the red-green, red-yellow, and the green-yellow group. There were no significant differences in personality traits between these colour pairs. 
Table 5. Personality traits and colour preferences. Pairwise comparisons of NCS primary chromatic colours: red-green, red-yellow, green-yellow. Multivariate analyses of variance (MANOVA).

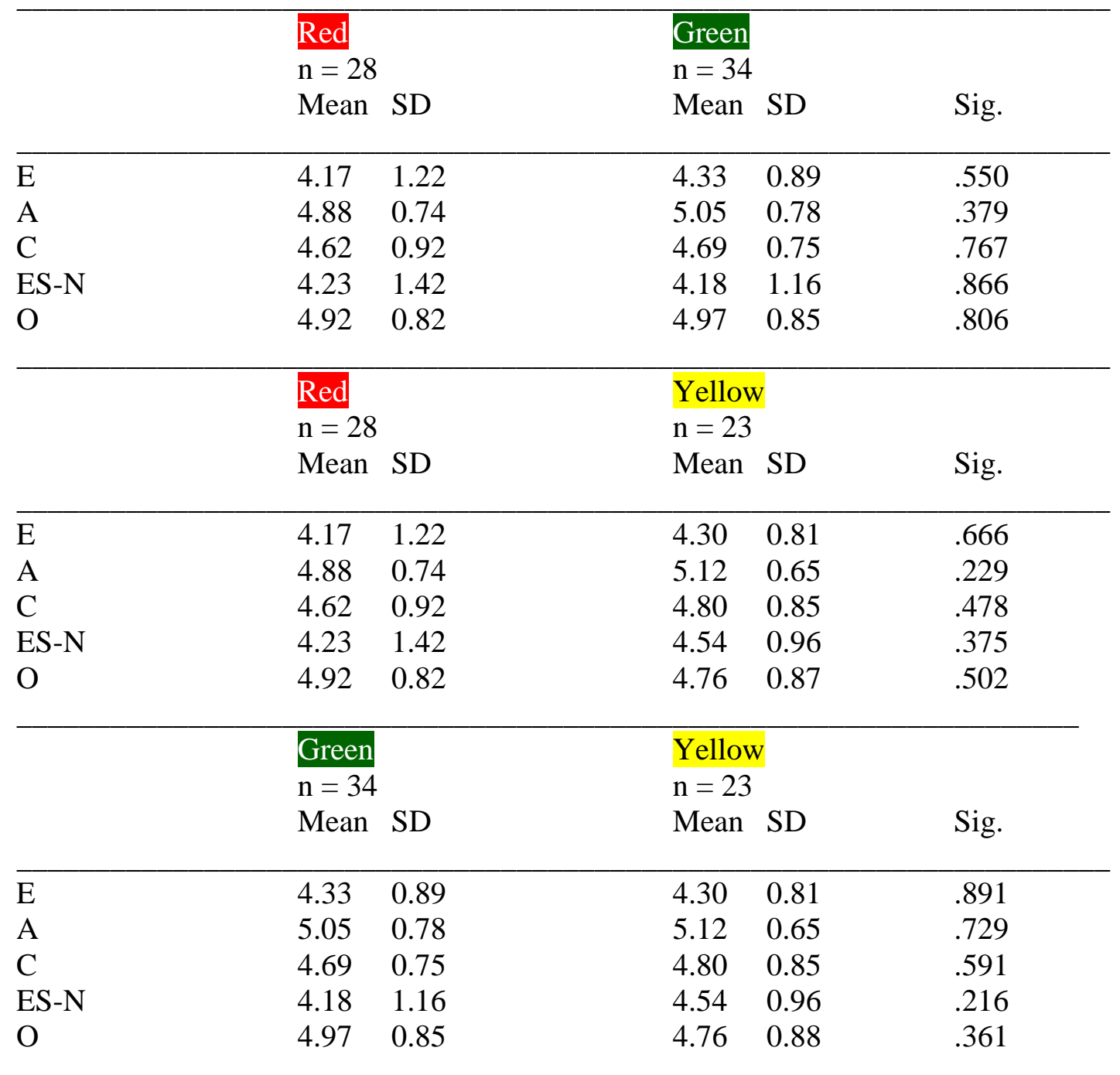

Note: $\mathrm{E}=$ extraversion; $\mathrm{A}=$ agreeableness $; \mathrm{C}=$ conscientiousness; $\mathrm{ES}=$ emotional stabilityneuroticism; $\mathrm{O}=$ openness to experience. Significant differences are marked in boldface.

\section{Discussion}

Our findings indicated that blue was the most preferred colour, yellow the least preferred. When the achromatic colours black and white were included, those two were even less preferred, and white was most disliked of all colours. The top preference of blue is in accordance with several studies [3,4,42-44]. Also children seem to have blue as a favourite 
[42]. So, blue seems to have a special status in terms of preferences, at least in the Western industrialized world.

In contrast to Hurlbert and Ling [8] and Jonauskaite, Dael, Chèvre, Althaus, Tremea, Charalambides and Mohr [6], but in agreement with Ou, et al. [45] we found no gender differences in preferences for chromatic colours. This finding suggest that culture could be an important factor in addition to biological differences related to the trichromacy or other biological underpinnings. We found chromatic colours are not gender coded in young Nordic adults, but black and white could be an exception. Those who preferred white were almost exclusively women, whereas the majority of those who had black as their favourite were men. However, the groups were small (15 and 16 for black and white, respectively) so the results should be interpreted with caution.

We found significant differences in personality traits for preferences three colours: blue, red, and green. Those who preferred blue had both higher agreeableness and extraversion scores than those preferring red, and higher agreeableness scores than those preferring green. There were no significant differences in colour preferences for openness, emotional stability-neuroticism, and conscientiousness, and no significant interaction with gender.

Why should blue have a special appeal to individuals with elevated agreeableness and extraversion scores? In part, agreeableness reflects individual differences in orientations toward interpersonal relationships. Individuals with high agreeableness scores are described as cooperative, forgiving, prefer social harmony, show positive affectivity and have strong empathic abilities [46]. Furthermore, they are likely to use negotiations to resolve conflicts, or withdraw from social conflicts, and they tend to avoid situations that are disharmonious $[47,48]$. Thus, the emotional profile of agreeableness and preference for blue align with 
reported emotions evoked from the colour blue. For example, using the Munsell colour system Valdez and Mehrabian [49] reported that colours in the blue-region were rated as the most pleasant hues, and purple-blue among the least arousing. Also Briki and Hue [50] found blue and green to be pleasurable, and considerably more than red. In other words, the pleasure and low arousing effects of blue are in accordance with elevated agreeableness and positive emotionality in extraversion. Indeed, a core element in extraversion is social attention [51] and behaviour being emotionally rewarding especially in terms of positive affectivity [52]. This assumption is also supported by the somewhat forgotten psychoanalytic Rorschach tradition where relationships between colours and affects are integrated in a clinical test (Rorschach ink blot test) and a theoretical and therapeutic framework [53]. In this tradition, blue and red signify different relations to affects. Red is related to intense affects (passionate love, rage, excitement etc.), whereas blue is associated with free and easy affect control and draws the subject into distance, since that colour is related to the distant sky, ocean, and mountains [54]. Finally, the blue group also had slightly higher agreeableness scores than the green group (5.34 vs, 505). This effect could be related to a higher arousal effect of green $[49,55]$.

Those who preferred red had lower agreeableness scores compared both to the rest of the colour groups. Low agreeableness is associated with hostility and aggression [56,57] which again is reflected in several common social behaviours such as yelling and screaming, getting into arguments and being oppositional. [58]. Thus, our results endorse previous investigations showing an association between red and hostility [32,59]. Lower agreeableness is also related to higher dominance, as shown both among adolescents and adults [60,61]. Hence, lower agreeableness among our subjects preferring the red hue could indicate a tendency to higher social dominance, an assumption which is also underscored by other investigations showing red to be strongly associated with social dominance and arousal 
$[50,62]$. Thus, red group could be more emotionally aroused than the other groups due to trait connected arousal level. However, although the red group had a lower agreeableness score (4.88) than the other groups (5.25), and especially the blue group (5.34), their scores were not in the low end of the scale reflecting disagreeableness (range of the scores $=1-7$ ).

Finally, how could colour preferences become part of the personality structure? One possibility could be spreading activation of memories. This semantic memory model proposes that mental elements (images, words etc.) are stored in memory associated with other memories in complex memory networks, including emotional memory networks [63]. Since colour preferences seem to be established in childhood [42] repeated experiences with the preferred colours could become part of individual's emotional memories associated with thoughts, beliefs, motives and behaviour [1] and integrated into emotional traits. In this way preferred colours could become part individuals' emotional style and behaviour and reflected in personality traits, such as agreeableness.

\subsection{Limitations}

The main limitation is the sample size yielding rather small groups for some of the preferred colours, for instance, yellow, black, and white. The study should therefore be repeated on a larger sample. We have also only used the six primary NCS colours including black and white due to the graphic quality of the colours. We thereby excluded other dimensions of colours such as variations in luminance and saturation, which are also relevant factors in terms of colour preferences [29].

\section{Conclusions}

The rank order of the colour preferences in the total sample for the six colours was as follows: blue, green, red, yellow, black, and white. There were no gender differences in 
preferences for the four chromatic colours, but significantly more women and men preferred white and black, respectively. There were significant differences in personality traits for individuals who preferred blue, red, and green. Compared to the rest of the sample, the blue group had higher scores on agreeableness and extraversion and the red group had lower scores on agreeableness. The pairwise comparison showed that the blue group had higher scores on agreeableness and extraversion compared to the red group, and higher scores on agreeableness compared to the green group. There were no significant personality differences for the other chromatic and achromatic colour groups. The personality differences in colour preferences are discussed according to differences in the emotional dimension of agreeableness and extraversion. 


\section{References}

1. Elliot, A.J.; Maier, M.A. Color psychology: Effects of perceiving color on psychological functioning in humans. Annual review of psychology 2014, 65, 95-120.

2. Jastrow, J. The popular aesthetics of color. Popular Science Monthly 1897, 50, 361-368.

3. Palmer, S.E.; Schloss, K.B. An ecological valence theory of human color preference. Proceedings of the National Academy of Sciences 2010, 107, 8877-8882.

4. Hurlbert, A.C.; Angela, O. Biological, cultural, and developmental influences on color preferences. In Handbook of Color Psychology, Elliot, A.J., Fairchild, M.D., Franklin, A., Eds.; Cambridge University Press: Cambridge, 2015; pp. 454-477.

5. Ellis, L.; Ficek, C. Color preferences according to gender and sexual orientation. Personality and Individual Differences 2001, 31, 1375-1379.

6. Jonauskaite, D.; Dael, N.; Chèvre, L.; Althaus, B.; Tremea, A.; Charalambides, L.; Mohr, C. Pink for girls, red for boys, and blue for both genders: Colour preferences in children and adults. Sex Roles 2019, 80, 630-642.

7. Adams, F.M.; Osgood, C.E. A cross-cultural study of the affective meanings of color. Journal of cross-cultural psychology 1973, 4, 135-156.

8. Hurlbert, A.C.; Ling, Y. Biological components of sex differences in color preference. Current biology 2007, 17, R623-R625.

9. Taylor, C.; Clifford, A.; Franklin, A. Color preferences are not universal. Journal of Experimental Psychology: General 2013, 142, 1015.

10. Welbourne, L.E.; Morland, A.B.; Wade, A.R. Human colour perception changes between seasons. Current Biology 2015, 25, R646-R647.

11. Laeng, B.; Brennen, T.; Elden, A.; Paulsen, H.G.; Banerjee, A.; Lipton, R. Latitude-ofbirth and season-of-birth effects on human color vision in the Arctic. Vision Research 2007, 47, 1595-1607.

12. Bowmaker, J.K. Evolution of colour vision in vertebrates. Eye 1998, 12, 541-547.

13. Jacobs, G.H. Evolution of colour vision in mammals. Philosophical Transactions of the Royal Society B: Biological Sciences 2009, 364, 2957-2967.

14. Sorokowski, P.; Sorokowska, A.; Witzel, C. Sex differences in color preferences transcend extreme differences in culture and ecology. Psychonomic bulletin \& review 2014, 21, 1195-1201.

15. Panorgias, A.; Parry, N.; McKeefry, D.; Kulikowski, J.; Murray, I. Gender Differences in Peripheral Colour Vision; A Colour-Matching Study. Investigative Ophthalmology \& Visual Science 2010, 51, 6288-6288.

16. Saito, M. Comparative studies on color preference in Japan and other Asian regions, with special emphasis on the preference for white. Color Research \& Application 1996, 21, 35-49.

17. Little, A.C.; Hill, R.A. Attribution to red suggests special role in dominance signalling. Journal of evolutionary psychology 2007, 5, 161-168.

18. Su, L.; Cui, A.P.; Walsh, M.F. Trustworthy Blue or Untrustworthy Red: The Influence of Colors on Trust. Journal of Marketing Theory and Practice 2019, 27, 269-281.

19. Mentzel, S.V.; Schücker, L.; Hagemann, N.; Strauss, B. Emotionality of colors: An implicit link between red and dominance. Frontiers in psychology 2017, 8, 317.

20. Elliot, A.J.; Niesta, D. Romantic red: red enhances men's attraction to women. Journal of personality and social psychology 2008, 95, 1150.

21. Elliot, A.J.; Niesta Kayser, D.; Greitemeyer, T.; Lichtenfeld, S.; Gramzow, R.H.; Maier, M.A.; Liu, H. Red, rank, and romance in women viewing men. Journal of Experimental Psychology: General 2010, 139, 399. 
22. Elliot, A.J.; Aarts, H. Perception of the color red enhances the force and velocity of motor output. Emotion 2011, 11, 445.

23. Cerbus, G.; Nichols, R.C. Personality variables and response to color. Psychological Bulletin 1963, 60, 566.

24. Tellegen, A. Personality traits: Issues of definition, evidence, and assessment. 1991.

25. Hughes, D.J.; Kratsiotis, I.K.; Niven, K.; Holman, D. Personality traits and emotion regulation: A targeted review and recommendations. Emotion 2020, 20, 63.

26. De Raad, B.; Kokkonen, M. Traits and emotions: A review of their structure and management. European Journal of Personality 2000, 14, 477-496.

27. Ng, W.; Diener, E. Personality differences in emotions: Does emotion regulation play a role? Journal of Individual Differences 2009, 30, 100-106.

28. Longua, J.; DeHart, T.; Tennen, H.; Armeli, S. Personality moderates the interaction between positive and negative daily events predicting negative affect and stress. Journal of Research in Personality 2009, 43, 547-555.

29. Gao, X.P.; Xin, J.H. Investigation of human's emotional responses on colors. Color Research \& Application: Endorsed by Inter-Society Color Council, The Colour Group (Great Britain), Canadian Society for Color, Color Science Association of Japan, Dutch Society for the Study of Color, The Swedish Colour Centre Foundation, Colour Society of Australia, Centre Français de la Couleur 2006, 31, 411-417.

30. Wu, Z.; Lin, T. Investigating the personality associations evoked by single colors: An exploratory study. Color Research \& Application 2017, 42, 388-396.

31. Gosling, S.D.; Rentfrow, P.J.; Swann Jr, W.B. A very brief measure of the Big-Five personality domains. Journal of Research in personality 2003, 37, 504-528.

32. Fetterman, A.K.; Liu, T.; Robinson, M.D. Extending color psychology to the personality realm: Interpersonal hostility varies by red preferences and perceptual biases. Journal of personality 2015, 83, 106-116.

33. Wiggins, J.S.; Trapnell, P.; Phillips, N. Psychometric and geometric characteristics of the Revised Interpersonal Adjective Scales (IAS-R). Multivariate Behavioral Research 1988, 23, 517-530.

34. Larsen, R.J.; Diener, E. Promises and problems with the circumplex model of emotion. 1992.

35. Remington, N.A.; Fabrigar, L.R.; Visser, P.S. Reexamining the circumplex model of affect. Journal of personality and social psychology 2000, 79, 286.

36. NCS. Natural Color System. Available online: https://ncscolour.com/ncs/?currency=eur (accessed on

37. Hård, A.; Sivik, L. NCS—Natural Color System: a Swedish standard for color notation. Color Research \& Application 1981, 6, 129-138.

38. Pastilha, R.C.; Linhares, J.M.; Rodrigues, A.I.; Nascimento, S.M. Describing natural colors with Munsell and NCS color systems. Color Research \& Application 2019, 44, 411-418.

39. Hård, A.; Sivik, L.; Tonnquist, G. NCS, natural color system-From concept to research and applications. Part I. Color Research \& Application 1996, 21, 180-205.

40. Engvik, H.; Føllesdal, H. The big five inventory på norsk [The big 5 inventory in Norwegian]. Tidsskrift for Norsk Psykologforening 2005, 42, 128-129.

41. Williams, J.R. The Declaration of Helsinki and public health. Bulletin of the World Health Organization 2008, 86, 650-652.

42. Terwogt, M.M.; Hoeksma, J.B. Colors and emotions: Preferences and combinations. The Journal of general psychology 1995, 122, 5-17. 
43. Yokosawa, K.; Schloss, K.B.; Asano, M.; Palmer, S.E. Ecological effects in crosscultural differences between US and Japanese color preferences. Cognitive Science 2016, 40, 1590-1616.

44. Dittmar, M. Changing colour preferences with ageing: A comparative study on younger and older native Germans aged 19-90 years. Gerontology 2001, 47, 219-226.

45. Ou, L.C.; Luo, M.R.; Woodcock, A.; Wright, A. A study of colour emotion and colour preference. Part I: Colour emotions for single colours. Color Research \& Application 2004, 29, 232-240.

46. Graziano, W.G.; Tobin, R.M. Agreeableness. In Handbook of individual differences in social behavior, Leary, M.R., Hoyle, R.H., Eds.; The Guilford Press: 2009; pp. 46-61.

47. Bresin, K.; Robinson, M.D. You are what you see and choose: Agreeableness and situation selection. Journal of Personality 2015, 83, 452-463.

48. Crowe, M.L.; Lynam, D.R.; Miller, J.D. Uncovering the structure of agreeableness from self-report measures. Journal of Personality 2018, 86, 771-787.

49. Valdez, P.; Mehrabian, A. Effects of color on emotions. Journal of experimental psychology: General 1994, 123, 394.

50. Briki, W.; Hue, O. How red, blue, and green are affectively judged. Applied Cognitive Psychology 2016, 30, 301-304.

51. Wolff, H.G.; Kim, S. The relationship between networking behaviors and the Big Five personality dimensions. Career Development International 2012.

52. Watson, D.; Clark, L.A. Extraversion and its positive emotional core. In Handbook of personality psychology; Elsevier: 1997; pp. 767-793.

53. Schachtel, E.G. On Color and Affect: Contributions to an Understanding of Rorschach's Test. II. Psychiatry 1943, 6, 393-409.

54. Schloss, K.B.; Palmer, S.E. Ecological aspects of color preference. In Handbook of color psychology, Elliot, A.J., Fairchild, M.D., Franklin, A., Eds.; Cambridge University Press: Cambridge, 2015; pp. 435-453.

55. Zieliński, P. An arousal effect of colors saturation: A study of self-reported ratings and electrodermal responses. Journal of Psychophysiology 2016, 30, 9.

56. McCrae, R.R.; Costa, P.T. The structure of interpersonal traits: Wiggins's circumplex and the five-factor model. Journal of personality and social psychology 1989, 56, 586.

57. Sanz, J.; Garcia-Vera, M.P.; Magán, I. Anger and hostility from the perspective of the Big Five personality model. Scandinavian Journal of Psychology 2010, 51, 262-270.

58. Wu, K.D.; Clark, L.A. Relations between personality traits and self-reports of daily behavior. Journal of Research in Personality 2003, 37, 231-256.

59. Robinson, M.D.; Liu, T.; Bair, J.L. Affect-related influences on color perception. In Handbook of color psychology, A. J. Elliot, M.D.F., \& A. Franklin, Ed.; Cambridge University Press: Cambridge, 2015; pp. 660-675.

60. Volk, A.A.; Provenzano, D.A.; Farrell, A.H.; Dane, A.V.; Shulman, E.P. Personality and bullying: Pathways to adolescent social dominance. Current Psychology 2019, 112.

61. Perry, R.; Sibley, C.G. Big-Five personality prospectively predicts social dominance orientation and right-wing authoritarianism. Personality and Individual Differences 2012, 52, 3-8.

62. Zajenkowski, M. Hostile and energetic: Anger is predicted by low agreeableness and high energetic arousal. PloS one 2017, 12, e0184919.

63. Foster, P.S.; Hubbard, T.; Campbell, R.W.; Poole, J.; Pridmore, M.; Bell, C.; Harrison, D.W. Spreading activation in emotional memory networks and the cumulative effects of somatic markers. Brain informatics 2017, 4, 85-93. 


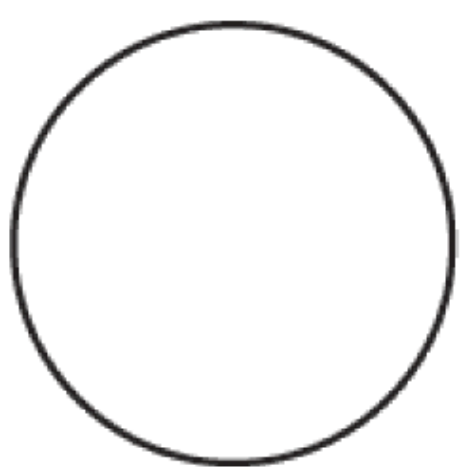

$\mathrm{W}$

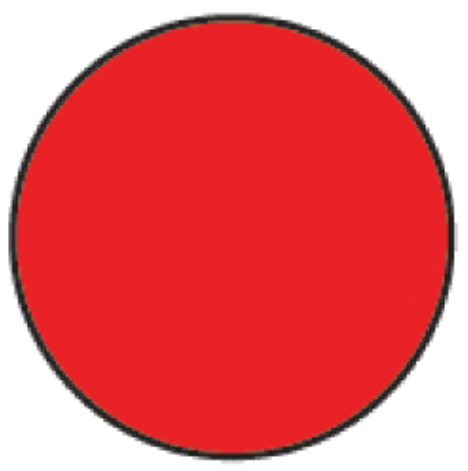

$\mathrm{R}$

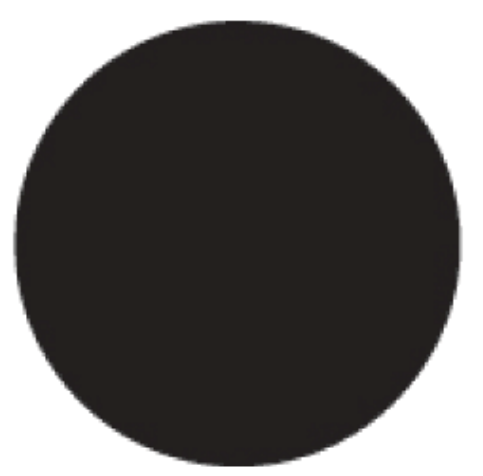

$\mathrm{S}$

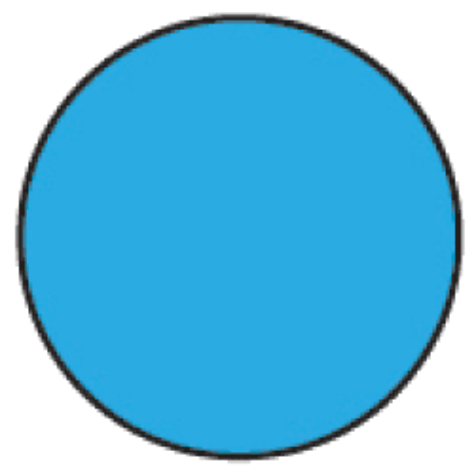

B

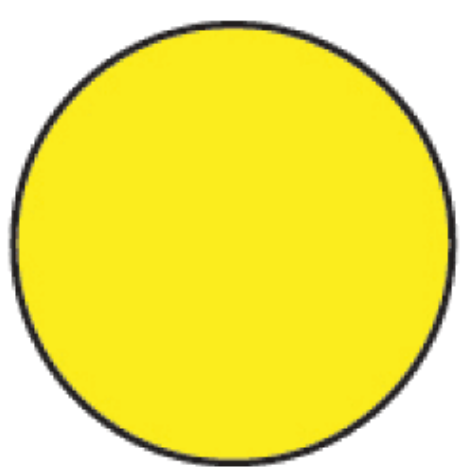

$\mathrm{Y}$

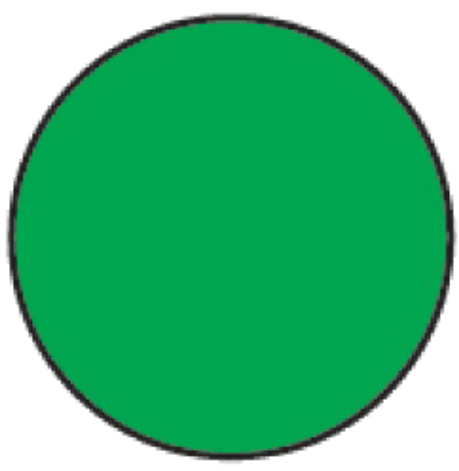

$\mathrm{G}$

Figure 1. Primary colours from the National Colour System (NCS). W = white, $\mathrm{S}=$ black, $\mathrm{Y}$ = yellow, $\mathrm{R}=$ red, $\mathrm{B}=$ blue, $\mathrm{G}=$ green. 